\title{
Prevalence of khat chewing and its effect on academic performance in Sidama zone, Southern Ethiopia.
}

\author{
Andargachew Kassa ${ }^{1}$, Eskindir Loha ${ }^{2}$, Atkilt Esaiyas ${ }^{3}$
}

1. School of Nursing and Midwifery, College of Medicine and Health Sciences, Hawassa University, Hawassa, Ethiopia

2. School of Public and Environmental Health, College of Medicine and Health Sciences, Hawassa University, Hawassa, Ethiopia

3. School of Medicine, Physiology Unit, College of Medicine and Health Sciences, Hawassa University, Hawassa, Ethiopia

\begin{abstract}
Background: Khat use is a well-established public health problem in Yemen, Arabian Peninsula, and Ethiopia. Along with its large scale production, the magnitude of khat use is increasing among students.

Objective: This study was intended to assess the prevalence, determinants, and effect of khat use on academic performance of high school students in Sidama Ethiopia.

Methodology: A cross-sectional study was conducted from April to June 2015. We used a stratified sampling technique to draw a total of 1,577students. The data was collected using self-administered questionnaires and analyzed using SPSS version 20. Descriptive statistics and logistic regression models were used to determine the prevalence, effects, and predictors of khat use.

Result: The life time and current prevalence of khat use were $14.6 \%$ and $13 \%$, respectively. Smoking cigarette $(\mathrm{AOR}=5.1,95 \%$ C.I: 2.3-14.3), drinking alcohol (AOR=3.0, 95\% C.I: 1.4-6.3), having a family growing khat (AOR=2.0, 95\% C.I: 1.1-2.5), having friend chewing khat $(\mathrm{AOR}=3.95 \%$ C.I: 2.0-4.6), were some of factors that increased the odds of students' khat use. Student's khat use increased the odds of student's poor academic performance (AOR $=2.1,95 \%$ C.I: 1.1-3.9).

Conclusion: The prevalence of khat use in high khat producing districts of Sidama and its contribution to poor academic performance demand prompt intervention.

Keywords: Khat, high school student, academic performance, Ethiopia.

DOI: https://dx.doi.org/10.4314/ahs.v17i1.22

Cite as: Kassa A, Loha E, Esaiyas A. Prevalence of khat chewing and its effect on academic performance in Sidama zone, Southern Ethiopia. Afri Health Sci. 2017;17(1): 175-185. https:// dx.doi.org/10.4314/ahs.v17i1.22
\end{abstract}

\section{Introduction}

Khat is known for its adverse health effects ${ }^{1,2}$. The growing research evidence shows that khat is a risk factor for different cardio-vascular disorders such as hypertension, ischemic heart diseases, and stroke $\mathrm{e}^{3,4}$. Khat is also a risk

\section{Corresponding author:}

Andargachew Kassa,

School of Nursing and Midwifery,

College of Medicine and Health Sciences,

Hawassa University, Hawassa, Ethiopia

Telephone: +2519-1133-8895

Fax number: +251-46-220-8755

P.O. Box: 1650,

Hawassa, Ethiopia

E-mail address: akandkassa@gmail.com, andkassa@hu.edu.et factor for poor oral health ${ }^{5}$, psychosis ${ }^{6}$, mental distress ${ }^{7}$, anemia $^{8}$, poor quality of life ${ }^{9}$, disturbed sleep pattern ${ }^{10-12}$, and duodenal ulcer ${ }^{13}$.

The adverse effect of khat on reproductive health includes genotoxic and teratogenic effects on the fetus, causing low birth weight ${ }^{14,15}$. Moreover, khat also affects the potency of male sexuality by affecting spermatogenesis and plasma testosterone concentration ${ }^{14,16}$. Growing evidence shows that khat use is one of the risk factors for taking risky sexual behaviors which fuel the widespread effect of sexually transmitted infections (STIs)especially Human Immunodeficiency Virus (HIV) infection ${ }^{17-19}$.

Besides khat's effect on mental, physical, and reproductive health, it is one of the factors causing socio-economic problems. These include; social isolation, family breakdown, neglect of social responsibilities ${ }^{20}$ and spending 
more than half of the domestic budget on $\mathrm{khat}^{21}$. In line with this, one study reported that khat use is associated with specific impairments in behavioral control which triggers conflict amongst human ${ }^{22,23}$. Moreover, khat is also reported as a risk factor for poor working memo$\mathrm{ry}^{24-26}$, poor academic performance ${ }^{27,28}$, reduced productivity and increased daily financial expenditure ${ }^{29}$. Despite these harmful consequences, the cultivation and use of khat is on arise especially in Yemen, Arabian peninsula, East Africa, and Ethiopia in particular ${ }^{30,31}$.

In Ethiopia, khat has started to rapidly replace the precious cereal, coffee, fruits and other crops found in the highlands of Ethiopia. Farmers prefer khat due to different reasons including, it's profitability as a cash crop than others, less vulnerability to drought, and less labor power cost required for its cultivation. However, khat producing farmers in Ethiopia start consuming khat and this culture is also continued expanding to the nearby secondary schools and urban dwellers ${ }^{29}$.

Khat or other psycho-active substance use at an early age leads to a complicated type of substance use in the remaining adulthood period of an individual. Youths' substance use, therefore, contributes to the creation of a community with; substance use dependence, juvenile delinquencies, crimes, socio-economic and other public health problems. The Magnitude of students' khat use in Ethiopia ranges from $13.4 \%$ to $41 \%$ for lifetime and $6.3 \%-33.1 \%$ for current (past 30 days) ${ }^{32}$. Among the top students' expressed reasons for khat use are; to get energized for study, to stay awake or avoid sleep and to increase academic performance ${ }^{32,33}$. Factors increasing the odds of students' khat use include; male gender, having friend chewing khat, having family members chewing khat, Muslim religion, pocket money, living alone during school age, cigarette smoking, financial freedom, parents' educational levels, living in rural area, and others ${ }^{32,34,35}$.

As one of the highlands of Ethiopia growing khat, Sidamazone has a lion's share of khat production and marketing. Almost most of the districts in the zone are khat producing. Especially, Aleta Chuko, Dale, Shebedino, and Wendo Genet districts are among the top of the list ${ }^{36}$. As a result, the trend which was observed in previously khat producing regions seems to happen in newly khat producing zones ${ }^{29}$. Nevertheless, as per the investigators best systematic and rigorous literature search, there is no published research report revealing the effects of khat production and marketing activities particularly on high school students of Sidama-zone. Therefore, this study was conducted to establish prevalence of khat use, factors affecting students' khat use, and also the effect of students' khat use on their academic performance.

\section{Method}

This study is institution-based and cross-sectional in design. It was conducted from April to June 2015 to assess the prevalence and factors determining khat chewing among high school students of Sidama zone, Southern Ethiopia. This study was conducted in Sidama zone. Sidama zone is one of the khat producing zones of Ethiopia located at the Southern Nations Nationalities and Peoples Region (SNNPR). The capital of the region is Hawassa town located $275 \mathrm{~km}$ south of Addis Ababa, the capital city of Ethiopia.

There are 21 districts in Sidama zone among which seven of them are top khat producing areas, according to the zonal agricultural office (personal communication). Considering the proportion of farmers growing khat, the first four high khat producing areas of the Zone were included: Shebedino District, Aleta Chuko District, Dara District and Wondo Genet District. During the study period, Sidama zone had 70,000 students enrolled in 40 high schools, of which 11 high schools were in the four selected districts. In total, there were 17.863 students enrolled in these high schools of which 8,645 were females. All districts had four high schools, except the three high schools in Wondogenet. Two in each district, a total of eight high schools, were selected by using simple random sampling technique.

Minimum sample size was determined using open EPI Software version 3.03. After calculating for all possible sample sizes, we selected the bigger sample size sufficient enough to address all research objectives. The bigger sample size obtained in this study was calculated using the reported proportions of khat chewing for urban(8.73\%) and rural $(4.52 \%)$ at $95 \%$ confidence level and power of $90 \%{ }^{37}$. The study from which we took the proportion showed that, living in an urban area was an exposure variable than living in rural. Thus, the calculated minimum sample size was 1,558 high school students. Considering $6 \%$ non response, the final minimum size was determined to be 1,655 students. 
The study participants were selected using stratified sampling technique.

Considering the relative size of students in each school, the sample size was distributed proportionately. Specific sections in each grade were selected by using simple random sampling technique. The stratification considered sex and grade levels of students to allocate students proportionally and on the assumption that student's grade level and sex would affect student's khat chewing behavior. The total sample size was distributed proportionally to the selected grades and sections based on total number of students in each year of study according to sex. Finally, individual students fulfilling the inclusion criterion were randomly selected to be study participants. The questionnaire was prepared by reviewing relevant literatures ${ }^{34,35,38}$. It was customized to fit the context and translated to the local language Amharic and Afo-Sidamu so that the students could understand the questions. A pre-test was performed on $10 \%$ of the sampled subjects at Tula High School found in Tula sub-city of Hawassa town. The questionnaires were distributed by trained data collectors.

The collected data was cleaned, coded, entered and analyzed using SPSS version 20.0 statistical software. Descriptive and summary statistics were done. Both bivariate and multivariate logistic regression analysis was used to determine the association of each independent variables with the dependent variable. The outcome variable 'Students' khat use' was a categorical variable with "Yes"/"No" re+sponse which follows a binomial distribution. Thus we checked the effects of the co-variates against this outcome variable. The list of co-variates include sex, student's grade level, living status during school age, parents educational level, family substance use history, peer influence, family pressure, other substance use history, having family growing khat, participating in khat production and marketing activities, amount of monthly pocket money, and living in urban or rural area.

We also assessed the effects of factors contributing for students' academic performance. This outcome variable is a categorical variable with possible responses such as "poor academic performance" and "better academic performance". Student past semester grades were used to classify student academic performance as "Poor" if he/ she scored $<50$ percent and "better" if it was $\geq 50 \%$. Covariates such as, sex, living area (with responses "Ur- ban" and "Rural"), father's educational status, student's participation in khat production and marketing activities, and student's current khat chewing status were all computed to see their effect on student's academic status.

On the outcome variables logistic regression model was fitted. Odds ratio with their 95\% confidence intervals were computed to identify the presence and strength of association and statistical significance was affirmed if $p<0.05$. To minimize the effect of confounding stratification was done by variables, which were assumed to have a confounding effect. In addition, multivariate analysis was used to control confounding variables. Variables that showed statistically significant association and main variables which could have an effect on the outcome were also included in the multivariate model. Those variables with $\mathrm{P}$ value $\leq 0.20$ were all considered in the multivariate analysis step.

The operational definitions given to the most important variables were defined as follows. 'lifetime khat use' defined as respondents who admitted to having ever used khat. "Current khat use" implying the proportion of students who used khat within 30 days preceeding the date of the study. 'Poor academic performance' denoted those students who scored, in their recent past semester exam, below $50 \%$ or failed in the previous semester.

Ethical clearance was obtained from Institutional Review Board of College of Medicine and Health Sciences, Hawassa University. To ensure voluntary participation of each participant, a written and signed informed consent (assent) was obtained from each student. Additionally, the confidentiality of the information was assured by using anonymous questionnaires and by maintenance of the data in a safe and protected place.

\section{Result \\ Socio-demographic characteristics of study partici- pants.}

This study included 1,577 high school students out of 1,655 sampled study participants making the response rate $95.3 \%$. The majority $479(54.5 \%)$ of the study subjects were male and 1,290 (79.9\%) of them were 15-19 years of age. The mean age of the respondents was 16.7 years $(\mathrm{SD}=2.3)$. One thousand seventy eight $(68.4 \%)$ of the respondents were protestant Christians, followed by orthodox $(11.6 \%)$. With regard to the ethnic group distribution the largest proportion belongs to Sidama 
ried where as very few $(6.7 \%)$ reported currently living in formal marital engagement (Table-1).

Table-1: Socio demographic characteristics of high school students in high khat producing areas of Sidama Zone, Southern Ethiopia 2015

\begin{tabular}{|c|c|c|}
\hline Socio demographic variables $(n=1577)$ & Frequency & Percent (\%) \\
\hline \multicolumn{3}{|l|}{ Woreda } \\
\hline Wendo Genet District & 198 & $12.6 \%$ \\
\hline Aleta Chuko District & 582 & $36.9 \%$ \\
\hline Shebedino District & & \\
\hline \multicolumn{3}{|l|}{ Grade } \\
\hline Grade 9 & 928 & $58.8 \%$ \\
\hline Grade 10 & 501 & $31.8 \%$ \\
\hline Grade 11 & 87 & $5.5 \%$ \\
\hline Grade 12 & 61 & $3.9 \%$ \\
\hline \multicolumn{3}{|l|}{ Sex } \\
\hline Male & 860 & $54.5 \%$ \\
\hline Female & 717 & $45.5 \%$ \\
\hline \multicolumn{3}{|l|}{ Age } \\
\hline $10-14$ & 148 & $9.4 \%$ \\
\hline $15-19$ & 1290 & $81.8 \%$ \\
\hline $20-24$ & 118 & $7.5 \%$ \\
\hline$>24$ & 21 & $1.3 \%$ \\
\hline \multicolumn{3}{|l|}{ Religion } \\
\hline Orthodox & 183 & $11.6 \%$ \\
\hline Protestant & 1078 & $68.4 \%$ \\
\hline Catholic & 120 & $7.6 \%$ \\
\hline Muslim & 55 & $3.5 \%$ \\
\hline Other & 109 & $6.9 \%$ \\
\hline \multicolumn{3}{|l|}{ Marital Status } \\
\hline Unmarried & 1366 & $86.6 \%$ \\
\hline Married & 106 & $6.7 \%$ \\
\hline Living together & 88 & $5.6 \%$ \\
\hline Divorced or separated & 11 & $0.7 \%$ \\
\hline Widower & 6 & $0.4 \%$ \\
\hline \multicolumn{3}{|l|}{ Ethnicity } \\
\hline Sidama & 1352 & $85.7 \%$ \\
\hline Non ethnic Sidama & 225 & $14.3 \%$ \\
\hline
\end{tabular}

Magnitude \& patterns of khat chewing, substance use, and sexual practices

The lifetime and current prevalence of khat use among high school students of Sidama zone were 230(14.6\%) and $205(13 \%)$ respectively. Out of current khat chewers
43(21.0\%) were female students. Among those students currently chewing khat, $64(31.2 \%)$ reported that they already developed an addiction to khat. But the vast majority of all students using khat, $164(80 \%)$ reported their desire to stop chewing khat (Table-2). 
Among those students currently using khat, 32(18.5\%) reported that they were chewing khat on a daily basis, whereas $12(5.9 \%)$ reported chewing khat 2-3 days per week. The proportion of students who chew khat once in a week was $62(30.2 \%)$. This makes the overall proportion of students who chew khat on a regular basis 112(54.6\%). The remaining 93(45.4\%) of students reported that they chew khat occasionally. The reported students' average financial expense for buying khat was 16.00 birr with an amount ranging from $1.00-100.00$ birr. These students also reported that they increase the amount of their khat use during times of an increased khat production (20.0\%) and also when khat prices get cheaper (17.6\%). Moreover the vast majority $(63.3 \%)$ of students chewed khat for greater than six months. Out of this $44.1 \%$ chewed khat for greater than one year.

This study further assessed the types of other substances used by high school students of Sidama zone. The findings of this study reveal that $59(3.7 \%)$ of students reported to have ever used alcohol whereas 38(2.4\%) had been smoking cigarettes in their life time. The shocking finding with respect to cigarettes is the information that almost all students who participated in this study $(80 \%)$ reported being exposed to second hand cigarette smoke (Table-2).

Table-2: Magnitudes and patterns of Sidama Zone highs school student's khat use, alcohol use, cigarette smoking, and sexual practices. Sidama, Ethiopia 2015.

\begin{tabular}{llll}
\hline Questions & & Frequency & Proportion (\%) \\
\hline Life time khat use & Yes & 230 & $14.6 \%$ \\
Current khat use & Yes & 205 & $13.0 \%$ \\
Developed an addiction to khat & Yes & 64 & $31.2 \%$ \\
Want to stop chewing khat & Yes & 164 & $80.0 \%$ \\
Current cigarette smoking & Yes & 38 & $2.4 \%$ \\
Current alcohol use & Yes & 59 & $3.7 \%$ \\
Ever practiced sex* & Yes & 280 & $17.8 \%$ \\
Commit sex due to khat use & Yes & 56 & $24.4 \%$ \\
Exposure to 2 $2^{\text {nd }}$ hand tobacco smoke & Yes & 1261 & $80.0 \%$ \\
\hline Ever practiced sex ${ }^{*}=>$ sex outside of formal marital engagement or premarital sex & &
\end{tabular}

The findings of this study also depicted the relationship between substance use and students' sexual practice. In light of this $56(24.4 \%)$ reported that they have sex as a result of their khat use. The overall students' sexual practice history, which was committed outside of formal marital engagement, was $280(17.8 \%)$. The proportion of students who commit casual and unprotected sex outside of formal marital engagement was $126(8.0 \%)$ (Table-2).

\section{Reasons for khat use}

The reported reasons for Sidama high school students' khat use were as follows. In accordance with their rank order the first reason mentioned was "to stay awake and get energized for study" (52.4\%). The remaining were; 'peer influence' $(27.2 \%)$, ' to avoid stress' $(8.4 \%)$, 'for getting happiness or pleasure' $(7.9 \%)$, and ' due to an addiction' $(4.2 \%)$.
Association of khat use with academic performance This study also examined whether students' khat use history had an influence on students' academic performance or not. The multivariate logistic regression analysis revealed that there is a statistically significant association $(\mathrm{AOR}=2.0,95 \% \mathrm{CI}: 1.1-3.9)$. As per this analysis the likelihood of performing poorly or failing in academics is two times higher for those students who were using khat currently than those who were not chewing khat. Other factors found increasing the odds of students' poor academic performance include, being female ( $\mathrm{AOR}=2.1$, 95\%CI: 1.3-3.6), living in urban area $(\mathrm{AOR}=1.7,95 \%$ CI: 1.1-2.7), and also having a father with academic status of elementary education and below $(\mathrm{AOR}=1.8,95 \% \mathrm{CI}$ : 1.1-3.1) (Table-3). 
Table 3: Binary \& multiple logistic regression analysis showing factors determining student's poor academic performance. Sidama Zone, Southern Ethiopia 2015

\begin{tabular}{|c|c|c|c|c|c|}
\hline \multirow[t]{2}{*}{ Variables } & & \multicolumn{2}{|c|}{$\begin{array}{l}\text { Academic } \\
\text { Performance }\end{array}$} & \multirow[t]{2}{*}{ COR (95.0\%C.I.) } & \multirow[t]{2}{*}{ AOR (95.0\% C.I.) } \\
\hline & & Poor & Better & & \\
\hline \multirow[t]{2}{*}{ Sex } & Female & 40 & 647 & $1.8(1.1-2.9)$ & $2.1(1.3-3.6)^{*}$ \\
\hline & Male & 28 & 832 & 1 & 1 \\
\hline \multirow[t]{2}{*}{ Living Area } & Urban & 40 & 693 & $1.7(1.0-2.8)$ & $1.7(1.1-2.7)^{*}$ \\
\hline & Rural & 28 & 816 & 1 & 1 \\
\hline \multirow{2}{*}{$\begin{array}{l}\text { Father's } \\
\text { educational } \\
\text { status }\end{array}$} & $\begin{array}{l}\text { Elementary } \\
\text { \& below }\end{array}$ & 48 & 867 & $1.8(1.1-3.0)$ & $1.8(1.1-3.1)^{*}$ \\
\hline & $\begin{array}{l}\text { High school } \\
\& \text { above }\end{array}$ & 20 & 642 & 1 & 1 \\
\hline \multirow{2}{*}{$\begin{array}{l}\text { Currently } \\
\text { chewing khat }\end{array}$} & Yes & 15 & 190 & $2.0(1.1-3.6)$ & $2.1(1.1-3.9)^{*}$ \\
\hline & No & 53 & 1319 & 1 & 1 \\
\hline \multirow{2}{*}{$\begin{array}{l}\text { Involvement in } \\
\text { khat production } \\
\text { \& marketing }\end{array}$} & Yes & 15 & 199 & $1.9(1.0-3.4)$ & $1.7(0.9-3.1)$ \\
\hline & No & 53 & 1310 & 1 & 1 \\
\hline
\end{tabular}

\section{Determinants of students khat use}

During the bivariate analysis, factors found to be significantly associated with alcohol use were: sex, living alone during school age, place of residence, having a family member chewing khat, having a family member smoking cigarettes, having a family growing khat, participating in khat production and marketing activities, drinking alcohol, smoking cigarettes, practicing sex, and having khat user friend/s. However, during the multiple logistic regression analysis: sex, having a family member chewing khat, having family member smoking cigarettes, having a family growing khat, drinking alcohol, smoking cigarettes, practicing sex, and having khat user friend/s were factors associated with khat chewing at statistically significant levels. Male students were 2.5 times more likely to have a khat chewing habit than females $(\mathrm{AOR}=2.5,95 \%$ CI: 1.6-3.8) (Table 4).
Those students who a had family history of khat use were two times more likely to have khat chewing than their counterparts (AOR $=2.0,95 \%$ CI: 1.2-3.0). Similarly, having a friend who used khat increased the odds of students chewing khat by three times more than those who didn't have a friends chewing khat (AOR $=3.1,95 \% \mathrm{CI}$ : 2.0-4.6). Most importantly, in contrast to students who had never smoked (AOR $=5.7,95 \% \mathrm{CI}$ : 2.3-14.3), smoking cigarettes increased the risk of students' khat chewing by about six fold.

Similarly, students' alcohol use also increased the risk of khat chewing by three fold, as compared to the students who did not drink alcohol (AOR $=3.0,95 \%$ CI: 1.4-6.3). In addition, having family growing khat was another factor that increased the risk of students' khat use by twofold. (AOR $=2.0,95 \% \mathrm{CI}: 1.1-2.5)$. Lastly, practicing sex was another factor which increased the odds of students khat use by two fold (AOR=2.0, 95\%CI: 1.3-3.0) (Table-4). 
Table 4: Bivariate and multivariate logistic regression analysis showing socio-demographic and behavioral correlates of current khat use among high school Students of Sidama Zone Ethiopia, June/July 2015

\begin{tabular}{|c|c|c|c|c|c|}
\hline \multirow[t]{2}{*}{ Variables } & & \multicolumn{2}{|c|}{ Used khat } & \multirow{2}{*}{$\begin{array}{l}\text { COR } \\
(95.0 \% \text { C.I. })\end{array}$} & \multirow{2}{*}{$\begin{array}{l}\text { AOR (95.0\% } \\
\text { C.I.) }\end{array}$} \\
\hline & & Yes & No & & \\
\hline \multirow[t]{2}{*}{ Sex } & Male & 162 & 43 & $3.6(2.6-5.2)$ & $2.5(1.6-3.8)^{*}$ \\
\hline & Female & 698 & 674 & $1^{\S}$ & 1 \\
\hline \multirow[t]{2}{*}{ Living Area } & Urban & 115 & 618 & $1.6(1.2-2.1)$ & $1.4(0.9-2.0)$ \\
\hline & Rural & 90 & 754 & 1 & 1 \\
\hline \multirow{2}{*}{ Lived alone during school age: } & Yes & 55 & 150 & $1.6(1.2-2.3)$ & $1.5(0.9-2.3)$ \\
\hline & No & 252 & 1120 & 1 & 1 \\
\hline \multirow[t]{2}{*}{ Family cigarette use history } & Yes & 18 & 187 & $3.9(2.5-6.1)$ & $1.8(0.9-3.4)$ \\
\hline & No & 42 & 1330 & 1 & 1 \\
\hline Family khat use & Yes & 64 & 141 & $3.9(2.8-5.5)$ & $2.0(1.2-3.0)^{*}$ \\
\hline history: & No & 142 & 1230 & 1 & 1 \\
\hline Having khat chewing & Yes & 85 & 141 & $6.2(4.5-8.6)$ & $3.1(2.0-4.6)^{*}$ \\
\hline friend & No & 120 & 1231 & 1 & 1 \\
\hline \multirow[t]{2}{*}{ Do your family grow khat } & Yes & 151 & 836 & $1.8(1.3-2.5)$ & $2.0(1.1-2.5)^{*}$ \\
\hline & No & 54 & 536 & 1 & 1 \\
\hline \multirow{4}{*}{$\begin{array}{l}\text { Involvement in khat production } \\
\text { and marketing } \\
\text { Smoking cigarette }\end{array}$} & Yes & 63 & 151 & $3.6(2.6-5.1)$ & $1.6(0.9-2.4)$ \\
\hline & No & 142 & 1221 & 1 & 1 \\
\hline & Yes & 24 & 14 & $14.2(7.2-28.1)$ & $5.7(2.3-14.3) *$ \\
\hline & No & 157 & 1303 & 1 & 1 \\
\hline \multirow[t]{2}{*}{ Drinking alcohol } & Yes & 32 & 27 & $9.2(5.4-15.8)$ & $3.0(1.4-6.3)^{*}$ \\
\hline & No & 173 & 1344 & 1 & 1 \\
\hline \multirow[t]{2}{*}{ Ever practiced sex } & Yes & 85 & 195 & $4.5(3.3-6.2)$ & $2.0(1.3-3.0)^{*}$ \\
\hline & No & 110 & 1134 & 1 & 1 \\
\hline
\end{tabular}

\section{Discussion}

This study determined the prevalence, determinants and effects of khat use among high school students of Sidama zone. The study tries to prevent anticipated social desirability bias by using a pre-tested self-administered questionnaire and giving adequate privacy to students while collecting the data using an anonymous questionnaire.

The overall life time and current prevalence of khat use among high school students of Sidama zone were 14.6\% and $13 \%$ respectively. In contrast to other study reports from outside of Ethiopia, the magnitude of khat use for Sidama zone high school students seems lesser. For instance the overall khat use prevalence registered in Saudi Arabia was $24 \%{ }^{35}$.

Similarly reports from Eastern part of Ethiopia documented a $25 \%$ for life time khat use prevalence ${ }^{34}$. Other school, university, and community based studies conducted in Ethiopia also reported a much higher figure than the reports we found among Sidama students ${ }^{32,34,38}$. For instance the reported overall khat use prevalence among Agaro high school students was $64 \%$. This is nearly five times bigger $(64 \%)$ than the Sidama high school students $^{38}$. However, our finding was similar with one research conducted on Ataye high school students of Ethiopia. The documented life time and current khat use prevalence from this nearby khat producing district called Gurage Zone, were $15.36 \%$ and $13.25 \%$ respectively ${ }^{37}$. Compared to Ethiopian university based khat survey reports, the prevalence for students of Sidama seems to fall within the documented khat use prevalence range but lesser than the community based reports. For instance university based prevalence studies conducted in Ethiopia reported khat use prevalence ranging from $13.4 \%$ to $41 \%$ for lifetime, $7 \%$ to $20.3 \%$ for past 12 months, and $6.3 \%$ to $33.1 \%$ current or past 30 days $^{32}$. Much bigger prevalence reports noticed in Ethiopia are from one school survey report and other community based surveys ${ }^{7,34}$.

In contrast to population based research reports of Ethiopia, khat use prevalence findings from our study seem lesser. To compare this, one can see the documented community based reports of Ethiopia which range from $31.7 \%-55.7 \%{ }^{34,39}$. The differences noticed in these research reports may better be explained with the following possible rationales. These may include, study time differences, methodological differences, availability or production of khat in the studied areas, the surrounding community socio-cultural and religious context, the time period in which khat got introduced to the local community, and the working legal and policy issues in the surrounding regions. 
One of the limitations of crosssectional surveys is their inability to tell the pattern or trend of the subject under study ${ }^{40}$. In accordance with this fact, our study never tried to assess the pattern and the rate in which Sidama students' khat use raised from zero to $14 \%$. Even though further studies are required in this area, as khat is new to the area, it is possible to understand that the prevalence increased with in a short period. If this is the case, the doubling and tripling time of the existing prevalence may be very soon.

The discovered prevalence in the area is at an alarming level and at more than sufficient level to establish khat use as one of the public health problems of the area. As most of khat chewing students' self-report depicted, most students already claimed developing an addiction to khat. They also expressed their desire to stop chewing khat. Thus, this is time for action by all concerned parties. As khat is a psycho-active substance, the reported prevalence is high enough to cause all the adverse outcomes mentioned in the introductory part of this article. It is also well known that using psycho-active substances in early age leads to using various drugs and continued use of substances in latter life.

In this study, we found only three types of substances currently used by the students. These were khat (13.0\%), alcohol $(3.7 \%)$, and cigarettes $(2.4 \%)$. This finding is consistent with other studies. Most of the studies conducted in Ethiopia reported students using these three psycho-active substances ${ }^{32,34}$. Nevertheless, looking merely at the size of the cigarette prevalence report is misleading. Because nearly all students in these districts (80\%) are passive cigarette smokers as a result of uncontrolled exposure to second hand tobacco smoke. This report may be taken as an indicator for the communities' exposure to second hand smoke. Ethiopia has already developed a policy and legal framework to safeguard citizens from exposure to second hand smoke. Our finding is, therefore, a confirmation that the implementation of the policies and reinforcement of the law are not to the expected level.

\section{Factors determining students' khat use}

As the multivariate logistic regression analysis denoted, being a male, having a family member chewing khat, drinking alcohol, smoking cigarettes, ever practicing sex, having a family growing khat, and having friend who chews khat were all factors increasing the odds of students khat use. Most important of all these, smoking cigarettes increased the risk of khat chewing by about six folds as compared to the students who had never smoked (AOR $=6.0,95 \%$ CI: 2.3-14.3).

These study findings are in accordance with other study reports. But unique to this study is that we considered additional factors such as having a family which grows khat, and students involvement in khat marketing activities $^{32,34,38}$. The result showed that both factors were significant at the binary logistic regression analysis level. Especially students' involvement in khat producing and marketing activities was significant with $(\mathrm{COR}=3.6, \mathrm{CI}$ : 95\% 2.6-5.1). However, only 'having a family growing khat' passed the multivariate analysis. In addition, we also assessed the effects of ever practicing sex on students 'khat use. The result denoted that students' odd of khat use is two times higher for those who ever practiced sex than those who didn't. Therefore considering those modifiable risk factors among the list of determinants shown above will help in designing khat use preventive programs.

\section{Effect of khat use on student's academic perfor- mance}

Most of studies conducted in Ethiopia and other countries reported that students are using khat for its stimulant effect. Among the self reported reasons given by students; to wake up or avoid sleep, to get energized for study, and to increase academic performance are includ$\mathrm{ed}^{32,34}$. In contrary to this, those khat chewing students in our study had a poor chance of performing well in their academics or in an other way had a likelihood of failing in their academics. That means scoring below 50\%.

Student's poor performance as a result of khat use is also in accordance with other study findings. These studies stated that khat use has an association with academic performance ${ }^{27,28,41}$. There are also other reports that documented the fact that other psychoactive substance use also increases the odds of students' poor academic performance or failure in academics ${ }^{42}$.

The paradox between the emerging evidence ascertaining khat's effect for poor academic performance and the frequent motivational beliefs held by students might happen as a result of lack of information or getting distorted information either from deeply embedded myths in the community or from formal or informal khat marketing promotional agencies. 
Other studies which assessed the association between khat and academic performance tested to discover if there was any association and determined the level of significance $\left(\mathrm{P}\right.$ value) and chi squared testing ${ }^{28}$. But this study goes further to determine to what extent khat use affect students 'academic performance using the multiple logistic regression analysis and found that khat using students had odds of failing in their academics or performing poorly by two folds more than the non-chewing students. But further studies like comparative cross-sectional studies, case control, or other longitudinal studies can be conducted to explain more about the issue and establish either cause and effect or temporal relationship. As limitation of all cross-sectional surveys, this study didn't intend to explain beyond determining the odds of students' poor academic performance due to khat use.

This study also showed that being female, living in an urban area, and having a father with educational status of elementary and below showed students' odds of failing in their academics by about two fold more than their counterparts. This may be due to female students' work burden at domestic level, the availability of leisure centers and psycho-active substances in the urban area, and also lack of parental mentorship and guidance from their uneducated or less educated fathers respectively.

Our primary research objectives were determining the prevalence and factors affecting students' khat use. As one of the limitations of this study we didn't exhaustively embrace all possible factors affecting students' academic performance. Among these factors, group of factors related to communication, learning facilities, availability of proper guidance, and presence of family related stressors are determinants reported by other study ${ }^{43}$. Since we also used students' self-report using the self-administered questionnaire, some students may fail to remember, that is, recall bias and/or intentionally misreport their last semester's cumulative grade point. Similarly, the prevalence we found in this research may be more than the report we found due to social-desirability bias.

\section{Conclusion}

The prevalence of khat use of high school students living in high khat producing and marketing districts of Sidama Zone is at an alarming level. Having a family growing khat, having a family member chewing khat, having a friend who chews khat, smoking cigarettes, drinking

African Health Sciences Vol 17 Issue 1, March, 2017 alcohol ,ever practicing sex, and being male are all factors increasing the odds of students' khat use. Students' khat use increased the odds of students' poor academic performance or failing in their academics. Similarly being female, living in an urban area \& having a father with an academic status primary education and below are factors increasing students' good academic performance.

\section{Recommendations}

Khat's contribution to students' poor academic performance demand prompt intervention. Formulation of appropriate intervention which reduces the use of khat should be everyone's priority. Moreover, designing an effective cessation strategy to help students with established khat addiction will remain the responsibility of the students, the family, the health authorities, education authorities, agricultural authorities and all other stakeholders.

\section{Acknowledgments}

Primarily, we are grateful to Hawassa University for funding this project and also all students participated in the study. We also would like to appreciate students participated in this study and all the data collectors who tried their best to collect the data in difficult time and remote places.

\section{Conflict of interest}

None to declare

\section{Reference}

1. Hassan NA, Gunaid AA, Murray-Lyon IM. Khat (Catha edulis): health aspects of khat chewing. East Mediterr Health J. May-Jun 2007;13(3):706-718. PubMed

2. Ageely HM. Health and socio-economic hazards associated with khat consumption. J Family Community Med. Jan 2008;15(1):3-11. PubMed

3. Al Suwaidi J, Ali WM, Aleryani SL. Cardiovascular complications of Khat. Clin Chim Acta. Apr 18 2013;419:1114.

4. Getahun W, Gedif T, Tesfaye F. Regular Khat (Catha edulis) chewing is associated with elevated diastolic blood pressure among adults in Butajira, Ethiopia: a comparative study. BMC Public Health. 2010;10:390.

5. Astatkie A, Demissie M, Berhane Y, Worku A. Oral symptoms significantly higher among long-term khat (Catha edulis) users in Ethiopia. Epidemiol Health. 2015;37:e2015009. 
6. Degraeve G. [Khat-induced psychosis?]. Tijdschr Psychiatr. 2007;49(10):763-767.

7. Damena T, Mossie A, Tesfaye M. Khat chewing and mental distress: a community based study, in jimma city, southwestern ethiopia. Ethiop J Health Sci. Mar 2011;21(1):37-45. PubMed

8. Kedir H, Berhane Y, Worku A. Khat chewing and restrictive dietary behaviors are associated with anemia among pregnant women in high prevalence rural communities in eastern Ethiopia. PLoS One. 2013;8(11):e78601. 9. Sheikh KA, El-Setouhy M, Yagoub U, Alsanosy R, Ahmed Z. Khat chewing and health related quality of life: cross-sectional study in Jazan region, Kingdom of Saudi Arabia. Health Qual Life Outcomes. 2014;12:44.

10. Robinson D, Gelaye B, Tadesse MG, Williams MA, Lemma S, Berhane Y. Daytime Sleepiness, Circadian Preference, Caffeine Consumption and Khat Use among College Students in Ethiopia. J Sleep Disord Treat Care. Dec 20 2013;3(1).

11. Nakajima M, Dokam A, Kasim AN, Alsoofi M, Khalil NS, al'Absi M. Habitual khat and concurrent khat and tobacco use are associated with subjective sleep quality. Prev Chronic Dis. 2014;11:E86.

12. Lemma S, Patel SV, Tarekegn YA, et al. The Epidemiology of Sleep Quality, Sleep Patterns, Consumption of Caffeinated Beverages, and Khat Use among Ethiopian College Students. Sleep Disord. 2012;2012:583510.

13. Raja'a YA, Noman TA, Al-Warafi AK, Al Mashraki NA, Al Yosofi AM. Khat chewing is a risk factor of duodenal ulcer. Saudi Med J. Sep 2000;21(9):887-888. PubMed 14. Mwenda JM, Arimi MM, Kyama MC, Langat DK. Effects of khat (Catha edulis) consumption on reproductive functions: a review. East Afr Med J. Jun 2003;80(6):318323. PubMed

15. Tariq M, Al-Meshal IA, Parmar NS, Ageel AM, Qureshi S. Evaluation of genotoxic potential of khat (Catha edulis) in Swiss albino mice. Mutagenesis. Sep 1986;1(5):381 -382. PubMed

16. Hakim LY. Influence of khat on seminal fluid among presumed infertile couples. East Afr Med J. Jan 2002;79(1):22-28. PubMed

17. Berhanu D, Go VF, Ruff A, Celentano DD, Bishaw T. Khat use among HIV voluntary counselling and testing centre clients in Ethiopia. Cult Health Sex. 2012;14(10):1197-1212.

18. Ayenew F, Tadesse T, Azale T. Alcohol and khat use as risk factors for HIV infection among visitors to volun- tary counselling and testing centres in Northwest Ethiopia. Trop Doct. Apr 2012;42(2):99 -100. PubMed

19. Berhan Y, Hailu D, Alano A. Polysubstance use and its linkage with risky sexualbehavior in university students: significance for policy makers and parents. Ethiop Med J. Jan 2013;51(1):13-23. PubMed

20. Omar YS, Jenkins A, Altena M, et al. Khat Use: What Is the Problem and What Can Be Done? Biomed Res Int. 2015;2015:472302.

21. Aden A, Dimba EA, Ndolo UM, Chindia ML. Socio-economic effects of khat chewing in north eastern Kenya. East Afr Med J. Mar 2006;83(3):69-73. PubMed 22. Colzato LS, Ruiz MJ, van den Wildenberg WP, Hommel B. Khat use is associated with increased response conflict in humans. Hum Psychopharmacol. May 2012;27(3):315321. PubMed

23. Bongard S, al'Absi M, Khalil NS, Al Habori M. Khat use and trait anger: effects on affect regulation during an acute stressful challenge. Eur Addict Res. 2011;17(6):285291.

24. Nakajima M, Hoffman R, Al'Absi M. Poor working memory and reduced blood pressure levels in concurrent users of khat and tobacco. Nicotine Tob Res. Mar 2014;16(3):279-287. PubMed

25. Hoffman R, al'Absi M. Working memory and speed of information processing in chronic khat users: preliminary findings. Eur Addict Res. 2013;19(1):1-6.

26. Colzato LS, Ruiz MJ, van den Wildenberg WP, Hommel B. Khat use is associated with impaired working memory and cognitive flexibility. PLoS One. 2011;6(6):e20602. 27. Al-Sanosy RM. Pattern of khat abuse and academic performance among secondary school and college students in jazan region, kingdom of saudi arabia (ksa). Journal of family \& Community Medicine. Sep 2009;16(3):89-95. PubMed

28. Ayana AM, Mekonen Z. Khat (Catha edulis Forsk) chewing, sociodemographic description and its effect on academic performance, Jimma University students 2002. Ethiopian Medical Journal. Apr 2004;42(2):125-136. PubMed

29. Feyisa TH, Aune JB. Khat Expansion in the Ethiopian Highlands: Effects on the Farming System in Habro District. Mountain Research and Development. May 2003;23(2):5 PubMed .

30. Al-Hebshi NN, Skaug N. Khat (Catha edulis)-an updated review. Addict Biol. Dec 2005;10(4):299 -307. PubMed 
31. Gebissa E. Khat in the Horn of Africa: historical perspectives and current trends. J Ethnopharmacol. Dec 1 2010;132(3):607-614.

32. Astatkie A, Demissie M, Berhane Y, Worku A. Prevalence of and factors associated with regular khat chewing among university students in Ethiopia. Subst Abuse Rehabil. 2015;6:41-50.

33. Gebrehanna E, Berhane Y, Worku A. Khat chewing among Ethiopian University Students--a growing concern. BMC Public Health. 2014;14:1198.

34. Reda AA, Moges A, Biadgilign S, Wondmagegn BY. Prevalence and determinants of khat (Catha edulis) chewing among high school students in eastern Ethiopia: a cross-sectional study. PLoS One. 2012;7(3):e33946.

35. Ageely HM. Prevalence of Khat chewing in college and secondary (high) school students of Jazan region, Saudi Arabia. Harm Reduct J. 2009;6:11.

36. Expert ZA. Interview With Expert in Sidama Zonal Agricultural Health Desk Bureau. In: Kassa A, Esayas A, eds. Sidama Zonal Agricultural Health Desk 2015.

37. Lakew A, Tariku B, Deyessa N, Reta Y. Prevalence of
Catha edulis (Khat) Chewing and Its Associated Factors among Ataye Secondary School Students in Northern Shoa, Ethiopia. Advances in Applied Sociology. 2014;4:9.

38. Adugna F, Jira C, Molla T. Khat chewing among Agaro secondary school students, Agaro, southwestern Ethiopia. Ethiop Med J. Jul 1994;32(3):161-166. PubMed

39. Alem A, Kebede D, Kullgren G. The prevalence and socio-demographic correlates of khat chewing in Butajira, Ethiopia. Acta Psychiatr Scand Suppl. 1999;397:84-91. 40. Polit DF, Beck CT. Nursing Research: Principles and Methods. Seventh ed: Lippinkot Williams and Willkins. 41. Kimani ST, Nyongesa AW. Effects of single daily khat (Catha edulis) extract on spatial learning and memory in CBA mice. Behav Brain Res. Dec 16 2008;195(1):192-197. 42. Cox RG, Zhang L, Johnson WD, Bender DR. Academic performance and substance use: findings from a state survey of public high school students. The Journal of school health. Mar 2007;77(3):109-115. PubMed

43. Mushtaq I, Khan SN. Factors Affecting Students' Academic Performance. Global Journal of Management and Business Research. 2012;12(9). 